Document downloaded from:

http://hdl.handle.net/10251/34852

This paper must be cited as:

Grau Meló, R.; Sánchez Salmerón, AJ.; Girón Hernández, LJ.; Ivorra Martínez, E.; Fuentes López, A.; Barat Baviera, JM. (2011). Nondestructive assessment of freshness in packaged sliced chicken breasts using SW-NIR spectroscopy. Food Research International. 44:331337. doi:10.1016/j.foodres.2010.10.011.

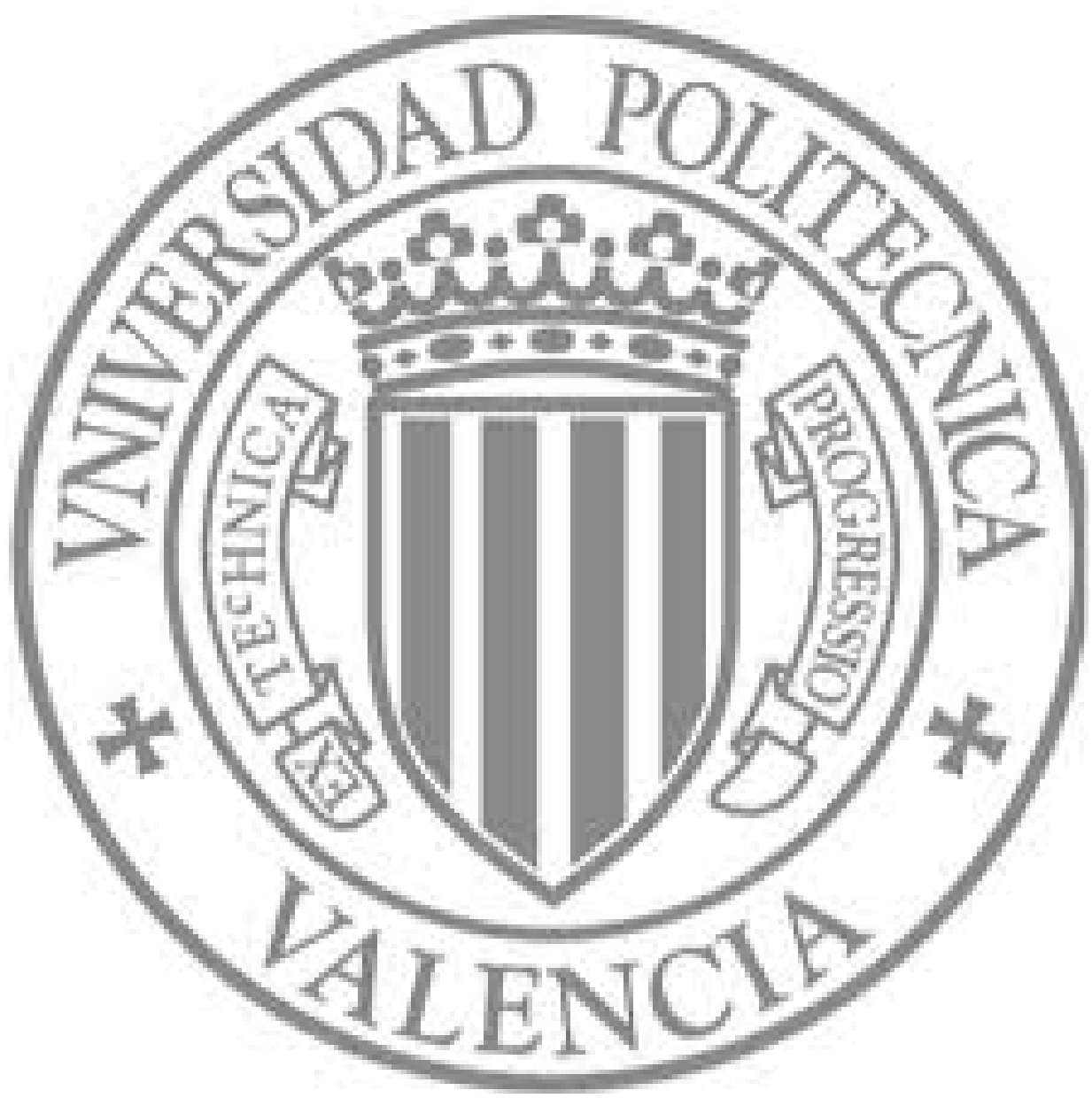

The final publication is available at

http://dx.doi.org/10.1016/j.foodres.2010.10.011

Copyright Elsevier 


\title{
Non-destructive assessment of freshness in packaged sliced chicken breasts using SW-NIR spectroscopy.
}

\author{
Raúl Grau $^{1}$, Antonio J. Sánchez ${ }^{2}$, Joel Girón ${ }^{1}$, Eugenio Iborra ${ }^{2}$, Ana Fuentes ${ }^{1}$, Jose M. Barat ${ }^{1}$. \\ ${ }^{1}$ Departamento de Tecnología de Alimentos. Universidad Politécnica Valencia, Spain. \\ ${ }^{2}$ Departamento de Ingeniería de Sistemas y Automática, Universidad Politécnica de Valencia, Spain
}

\begin{abstract}
A technique was developed to predict the freshness of packaged sliced chicken breast employing a nondestructive visible and short-wavelength near infrared (SW-NIR) spectroscopy method. Spectra were recorded at 0, 7 and 14 days using a camera, spectral filter $(400-1000 \mathrm{~nm})$ and a halogen flood lighting system which were developed and calibrated for the purpose. Physicochemical, biochemical and microbiological properties such as moisture $\left(\mathrm{x}^{\mathrm{w}}\right)$, water activity $\left(\mathrm{a}_{\mathrm{w}}\right), \mathrm{pH}$, total volatile basic nitrogen (TVB-N), ATP breakdown compounds $\left(\mathrm{K}_{1}\right.$ values) and mesophilic bacteria (cfu $\left.\mathrm{g}^{-1}\right)$ were determined to predict freshness degradation. The spectra obtained were related to the storage time of the samples. The best wavelengths for modeling freshness were 413, 426, 449, 460, 473, 480, 499, 638, 942, 946, 967,970 and $982 \mathrm{~nm}$. A linear correlation was found between the visible and SW-NIR spectroscopy and parameters such as microbiological counts, $\mathrm{K}_{1}$ and $\mathrm{T}-\mathrm{VBN}$ indexes.
\end{abstract}

Keywords: spectroscopy, SW-NIR, freshness, chicken meat, packaging

\section{INTRODUCTION}

Consumption of chicken has increased in many countries as it is related to a more health conscious diet and mainly due to it being a relatively inexpensive protein source, which is ideally suited to the many forms of convenience foods in the modern western diet (Ellis \& Goodacre, 2001).

In the meat sector, as well as in other food sectors, there is a demand for fresh and ready to use products, or at least easy to prepare, which explains the popularity of packaged fresh chicken fillets. The booming demand for sliced packaged chicken requires the intensive handling of the product to give it the necessary format and causes a certain loss of freshness. During processing (quartering, skinning, cutting and boning), bacteria on the skin and in the carcass cavity of the chicken are the main cause of spoilage (Alain \& Stéphane, 2008).

Food safety is a main concern for consumers. Present economic trends lead to increasing distances between consumption and productions zones and consequently to an extension of the delivery chain. Considering these changes, it is necessary to set out methods for objective reliable safety control, guaranteeing quality and freshness at all stages of the commodity chain (Dufour, Frencia, \& Kanea, 2003).

Freshness is a rather ambiguous term when referring to meat and fish products. Currently there is no methodology to determine meat freshness, but there are non-legislated tests that provide guidance on the subject. Various methods for assessing meat freshness have been developed based on the measurement of postmortem deteriorative changes associated with sensory quality, microbial growth (Kaneki et al., 2004, Barat et al., 2008) and chemical changes, such as $\mathrm{pH}$ or total volatile basic nitrogen (TVB$\mathrm{N})$. The concentration of ATP and its degradation products (inosine-5'-monophosphate (IMP), inosine (Ino), and hipoxantine $(\mathrm{Hx})$ ) has been widely used in fish freshness control (Karube, Matsuoka, Suzuki, Watanabe, \& Toyama, 1984; Surette, Gill, \& Leblanc, 1988; Barat et al., 2008; Fernández-Segovia, Escriche, \& Serra, 2008). Watanabe, Tsuneishi, and Takimoto (1989) stated that the analysis of ATP and its breakdown products could be used as an indication of meat freshness. However, the determination of these compounds in meat has been performed mainly to correlate them with sensory qualities or with different post-mortem meat quality, or to test the effect of $\mathrm{a}_{\mathrm{w}}$ and temperature on the IMP degradation (Mateo, Domínguez, Aguirrezábal, \& Zumalacárregui, 1996; Flores, Armero, Aristoy, \& Toldrá, 1999; Kavitha \& Modi, 2007). Among the ATP derivatives, IMP is predominant in meat extract $24 \mathrm{~h}$ after slaughter. This compound is gradually transformed into inosine and hypoxanthine in the meat (Watanabe et al., 1989).

Sensory evaluation is, in most cases, subjective and costly. Microbial methods estimating bacterial spoilage (Dalgaard, 1995) and chemical methods encounter problems in measuring early postmortem deterioration, so that rapid and simple methods for meat freshness estimation are required (In-Seon, Yong-Jin, \& Namsoo, 
2000; Kaneki et al., 2004; Zhang, Jin, Dong-hui, \& Yubin, 2008).

Spectroscopic methods have gained importance in the evaluation of food quality attributes during the last decades (Nádai, 1983; Nádai \& Mihályi-Kengyel, 1984). The fact that NIR spectra reflect several parameters of the material suits the method for evaluating complex quality (Williams \& Norris, 2001). Short-wave near-infrared (NIR) spectroscopy shows promise for fast and nondestructive analysis of biological materials (Di, Yong $\&$ Shuijuan, 2008). As they have high reflectance ability in the region of 780-1040 nm, the short-wave NIR spectra are being applied to construct excellent detectors for the nondestructive component determination in biological materials. The short-wave NIR region allows NIR energy to penetrate more deeply into a sample with much less heating effect than the long-wave NIR region (1100-2500 $\mathrm{nm})$. Also, short-wave NIR spectra can be measured with inexpensive light sources (tungsten lamps) and detectors (silicon diode array) (Mayes \& Callis, 1989). Various near infrared spectroscopic methods have also been published on prediction of sensory quality criteria (Warm, Martens, \& Nielsen, 2001), evaluation of freshness (Nilsen Esaiassen, Heia, \& Sigernes, 2002) or detection of fish spoilage (Lin, Mousavi, Al-Holy, Cavinato \& Rasco, 2006). Diffuse reflectance spectroscopy has also been used to evaluate the quality of frozen minced red hake (Pink, Naczk, \& Pink, 1999), detection and quantification of microbial spoilage of chicken meat (Ellis, Broadhurst, \& Goodacre, 2002; Lin et al., 2004) and monitoring the shelf-life of dairy products (Sinelli, Barzaghi, Giardina, \& Cattaneo, 2005; Sinelli, 2006). However, in most of these studies samples were manipulated (minced, placed in Petri dishes, etc), thus changing their structure and the format in which the meat is marketed. The aim of this study was therefore to develop and evaluate the feasibility of visible short-wavelength near-infrared (SW-NIR) as a nondestructive method for determining the freshness of sliced and commercially packaged chicken breasts.

\section{MATERIALS AND METHODS}

The study was carried out using 50 broiler chicken breasts, which were obtained directly from a local poultry processing plant $24 \mathrm{~h}$ after slaughter. The pieces, without fat and skin tissue, were cut, to replicate commercial slices, into slices of $200 \mathrm{~g}$ each with a thickness of $20 \mathrm{~mm}$. Three slices per chicken breast sample were handled aseptically and packed randomly in a plastic tray sealed with plastic film $(n=45)$.

During the shelf-life study, the quality of the broiler chicken cuts was evaluated as a function of film packaging and storage time. The time points for the evaluation were 0 days (immediately after packaging) and after 7 and 14 days of storage at $4^{\circ} \mathrm{C}$.

Image analysis (visual and SW-NIR) was carried out at day 0 in all samples before and after packaging and before and after opening $(\mathrm{n}=10)$ at 7 and 14 days. Opening was done in aseptic conditions in order to take samples for the microbiological analysis. The unpackaged samples were also used for the subsequent analyses (physicochemical and nucleotides monitoring). Additionally, the 15 remaining samples were used for microbial and nucleotides monitoring at days 3, 9 and 12 .

\subsection{Destructive analyses.}

\subsubsection{Analytical determinations}

Moisture $\left(\mathrm{x}^{\mathrm{W}}\right)$ was measured by oven drying to constant weight at $100^{\circ} \mathrm{C}$ (UNE -EN ISO 1442:1979). Water activity $\left(\mathrm{a}_{\mathrm{w}}\right)$ was analyzed with an Aqualab GB-X Fast-Lab (GBX, Romans-sur-Isère, France) equipment, working at a temperature of $25^{\circ} \mathrm{C}$. For the determination of $\mathrm{pH}$, solutions of $10 \mathrm{~g}$ of homogenized chicken meat and $90 \mathrm{ml}$ of distilled water were measured with a portable $\mathrm{pH}$ meter MM40 (Crison Instruments S. A, Alella, Barcelona, Spain) following the procedure proposed by Fuentes et al 2008. Total Volatile Basic Nitrogen (TVB-N) was determined according to the procedures described by Malle \& Tao (1987).

\subsubsection{Nucleotides Analysis}

The ATP-related compounds, consisting of inosine-5'monophosphate (IMP), inosine (Ino) and hipoxantine (Hx), were assayed by HPLC according to the method described by Barat et al. (2008), with some minor modifications.

\section{- Extraction of nucleotides}

The method used to the extraction was similar to that described by Burns \& Kee (1985). The entire extraction procedure was performed at $4{ }^{\circ} \mathrm{C}$. Five $\mathrm{g}$ of muscle were mixed with $50 \mathrm{~mL}$ of $0.6 \mathrm{M} \mathrm{HClO}_{4}$, and homogenized for $4 \mathrm{~min}$ in a masticator (IUL Masticator, Barcelona, Spain). The contents of the stomacher bag were immediately transferred to a centrifuge tube and centrifuged at $12,000 \mathrm{~g}$ for $10 \mathrm{~min}$ in a refrigerated Medifriger BL centrifuge (JP Selecta, S.A., Barcelona, Spain). The supernatant was filtered through glass wool, neutralized with solid potassium carbonate and left to stand in ice for $5 \mathrm{~min}$. The neutral extract was centrifuged at $12,000 \mathrm{~g}$ for $10 \mathrm{~min}$. The supernatant was stored at $-20^{\circ} \mathrm{C}$ until analysis.

A total of 2 extracts were obtained per sample.

\section{- $\quad$ HPLC analysis}

The analysis was conducted on a liquid chromatograph Jasco (Milano, Italy) with pump (model PU-1580), autosampler (model AS-1555-10), ternary gradient unit (model LG-1580-02), degasser unit (model DG-1580-54), and diode array detector (model MD-1510). Data acquisition was performed with ChromPass software version 17.403.1 (Jasco). Separations were achieved on a reverse-phase Ultrabase $\mathrm{C}_{18} 250 \times 4.6 \mathrm{~mm}$, internal particle diameter of 5 $\mu \mathrm{m}$ (Análisis Vínicos, S.L., Tomelloso, Spain). A guard column containing the same $\mathrm{C}_{18}$ packing as above was positioned in front of the analytical column to protect it from contamination. 
The composition of mobile phases was different for $\mathrm{Hx}$ and for both Ino and IMP analyses. To analyse Hx, mobile phase A was $0.1 \%$ of trifluoroacetic acid (TFA) in water; mobile phase B was $0.085 \%$ of TFA in $60 \%$ acetonitrile in water. For the Ino and IMP analyses, mobile phase A was $0.01 \mathrm{M}$ dipotassium hydrogen phosphate buffer, $\mathrm{pH} 4.5$; mobile phase $\mathrm{B}$ was $60 \%$ acetonitrile in water. Flow rate of mobile phase was $0.9 \mathrm{~mL} / \mathrm{min}$ in all cases. Injection volume was $20 \mu \mathrm{L}$. The elution program in both cases is shown in Table 1. The chromatograms were monitored at a wavelength of $254 \mathrm{~nm}$.

\section{Table 1.}

Elution program for HPLC analysis.

\begin{tabular}{ccc}
\hline Time $(\min )$ & Mobile phase A $(\%)$ & Mobile phase B $(\%)$ \\
\hline 0 & 98 & 2 \\
15 & 93 & 7 \\
16 & 0 & 100 \\
26 & 0 & 100 \\
27 & 98 & 2 \\
42 & 98 & 2 \\
\hline
\end{tabular}

A: $0.1 \%$ of trifluoroacetic acid (TFA) in water for $\mathrm{Hx}$ analysis, and 0.01 $\mathrm{M}$ dipotassium hydrogen phosphate buffer, $\mathrm{pH} 4.5$, for Ino and IMP analysis.

B: $0.085 \%$ of TFA in $60 \%$ acetonitrile in water for $\mathrm{Hx}$ analysis, and $60 \%$ acetonitrile in water for Ino and IMP analysis.

\section{- Identification and quantification}

Compounds were identified using retention time comparison of unknowns with those of standards and by standard addition or "spiking" (Johnson \& Stevenson, 1978). IMP, Ino, and Hx standards were obtained from Sigma-Aldrich (St. Louis, MO, USA). Standards solutions were prepared in $0.6 \mathrm{M} \mathrm{HClO}_{4}$ neutralised with solid potassium carbonate.

IMP, Ino, and Hx were quantified according to the external standard method, using calibration curves of peak area of compound $v s$ concentration of compound, under identical chromatographic conditions. $\mathrm{K}_{1}$-values were calculated according to the Equation (1):

$$
\mathrm{K}_{1}(\%)=\frac{\mathrm{Ino}+\mathrm{Hx}}{\mathrm{IMP}+\mathrm{Ino}+\mathrm{Hx}} \times 100
$$

where IMP is inosine 5'-monophosphate; Ino, inosine; Hx, hypoxanthine.

\subsubsection{Microbiological analysis}

The aerobic plate counts (expressed as $\mathrm{cfu} \mathrm{g}^{-1}$ ) were estimated following the method proposed by the UNE EN ISO 4833:2003. Tenfold dilutions in $0.1 \%$ peptone water were prepared from each sample obtained from every container on every measurement day $(n=3)$ and 1 $\mathrm{ml}$ aliquots were plated in duplicate. Aerobic counts were determined by using Plate Count Agar (Merck, Darmstadt, Germany). Duplicate pour plates were prepared per dilution and incubated at $28^{\circ} \mathrm{C}$ for $48 \mathrm{~h}$.

All destructive analyses were done in triplicate after grinding and homogenizing of samples.

\subsection{Non-destructive analysis. Spectra collection.}

Images were taken using a CCD $102 \mathrm{f}$ camera (Basler Vision Technologies., Ahrensburg, Alemania) and Specim ImSpector V10 1/2" filter (Specim Spectral Imaging, LTD., Oulu, Finlandia), which works like a linear multispectral camera. The illuminants were two halogen lamps 50W 230V HI-SPOT (Havells Sylvania, Gennevilliers, France) producing an indirect light to reduce reflections (Fig. 1). The position of the illuminant and camera to the sample was always constant to control the lighting conditions and to obtain a constant image size. The distance between the illuminant and the sample was $18 \mathrm{~cm}$, with a distance of $40 \mathrm{~cm}$ between the camera and the sample. The image (scanned line) obtained was composed of 256 gray levels (8 bits). The diffuse reflectance spectrum was collected using 1040 different wavelengths (each wavelength is digitalized by 8 bits). These wavelengths are distributed at intervals of 0.5769 $\mathrm{nm}$ in the range from 400 to $1000 \mathrm{~nm}$. The scanned line is composed of 1392 points, so that an image is grabbed with the resolution of 1392 x 1040 pixels. Reflectance data were stored as $\log (1 / \mathrm{R}), \mathrm{R}$ being reflectance. The instrument was operated by the software pylon Viewer 2.1.0.1664 (Basler Vision Technologies, Ahrensburg,Germany).

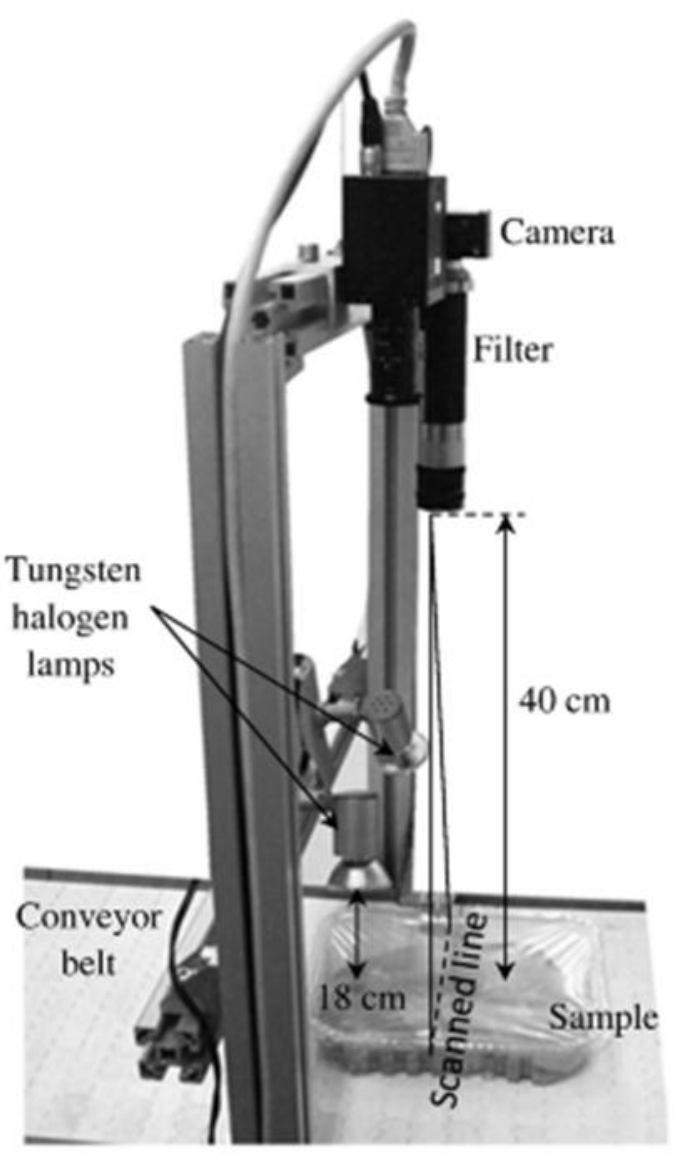

Fig 1. Spectral acquisition setups. 


\subsection{Statistical analysis.}

The effect of storage time on the variables (TVB-N, $\mathrm{x}^{\mathrm{w}}, \mathrm{a}_{\mathrm{w}}, \mathrm{K}_{1}$ and $\left.\log \left(\mathrm{cfu} \mathrm{g}^{-1}\right)\right)$ was subjected to a variance study (ANOVA). In order to describe the relation between the variables and storage time, a multiple regression analysis and the forward selection method were used. The influence of packaging film and storage time on the spectra values was evaluated using a discriminate analysis. Spectra data obtained for samples without packaging film were labeled "WPF" and those with packaging film "PF". Partial Least Squares Discriminant Analysis (PLSDA) (Martens \& Naes, 1989; Brereton, 1992; Wallays, Missotten, De Baerdenmaeker, \& Saeys, 2009) was employed to obtain predictive methods of calibration and storage time. Samples were selected at random from two groups; three quarters of the total samples were used for calibration and cross-validation and the remainder to test. The main selected wavelengths were obtained from the IPLSDA genetic algorithm of interval selection (Holland, 1975).

The relationship between the spectra and the values obtained from the destructive analyses was obtained by partial least square regression (PLS) (Bharati \& Champagne, 2004).

All statistical procedures were performed on the Matlab software package (The Mathworks, Natick, Massachussets, USA).

\section{Results and discussion}

\subsection{Destructive analyses}

The results of the destructive analyses of packed and sliced chicken breasts with standard deviations (S.D.) on days $0,7,14$ at $4{ }^{\circ} \mathrm{C}$ are shown in Table 2 . For all parameters except moisture $\left(\mathrm{x}^{\mathrm{w}}\right)$ there was a significant difference $(\mathrm{P}<0.05)$ with storage time. The influence of sampling time was therefore evaluated.

The values of water activity in the chicken samples increased from 0.986 to 0.987 during the first week and to 0.993 after 14 days $(\mathrm{P}<0.05)$. This could have been due to the enzymatic action on proteins, which would reduce water retention capacity (Huff-Lonergan \& Lonergan, 2005; Zhang, Lonergan, Gardner \& Huff-Lonergan, 2006). TVB-N is a parameter regulated by the Economic European Community (EEC, 2005) for some fish species such as Salmo salar and the Pleuronectidae family (except Greenland halibut), Merluciidae and Gadidae, among others. Although TVB-N is not regulated for chicken meat, this parameter can give information on biochemical changes occurring during product storage. The results showed that there was a significant increase in TVB-N values with time $(\mathrm{P}<0.05)$, doubling the initial content in 14 days (Table 2). As the limit set for fish is $30 \mathrm{mg} / 100 \mathrm{~g}$, after 14 days under the conditions of the experiment the samples were no longer fit for human consumption. Similar values have been found by other authors (Economou Pournis, Ntzimani, \& Savvaidis, 2009).
The aerobic plate counts (APC) increased significantly during storage (Fig. 2). Although European legislation does not set microbiological limits, except for salmonella (EEC, 2007), some authors recommend different limits to classify meat quality. Values lower than $10^{-6} \mathrm{cfu} \mathrm{g}^{-1}$ would indicate good quality meat (Pascual \& Calderón, 2000). APC counts between $10^{-6}$ and $10^{-7} \mathrm{cfu} \mathrm{g}^{-1}$ would have acceptable quality and counts higher than $10^{-7} \mathrm{cfu}^{-1}$ would be unacceptable (Smolander, Alakomi, Ritvanen, Vainiompää, \& Ahvenainen, 2004). According to these limits, sliced chicken breasts could be commercialized for a period between 9 and 12 days after packaging.

Table 2.

Water $\left(\mathrm{x}^{\mathrm{w}}\right)$, water activity $\left(\mathrm{a}_{\mathrm{w}}\right), \mathrm{pH}, \mathrm{TVB}-\mathrm{N}$, parameter $\mathrm{K}_{1}$ and aerobic plate counts $\left(\log \mathrm{cfu} \mathrm{g}^{-1}\right)$ and the standard deviation (SD) of the packaged sliced chicken breasts during storage ( 0,7 and 14 days).

\begin{tabular}{lccc}
\hline & \multicolumn{3}{c}{ Time (days) } \\
\cline { 2 - 4 } & 0 & 7 & 14 \\
\hline $\mathrm{x}^{\mathrm{w}} \pm \mathrm{SD}$ & $74.95 \pm 0.44 \mathrm{a}$ & $75.16 \pm 0.48 \mathrm{a}$ & $75.48 \pm 0.25 \mathrm{a}$ \\
$\mathrm{a}_{\mathrm{w}} \pm \mathrm{SD}$ & $0.986 \pm 0.00 \mathrm{a}$ & $0.987 \pm 0.00 \mathrm{~b}$ & $0.993 \pm 0.00 \mathrm{c}$ \\
$\mathrm{pH} \pm \mathrm{SD}$ & $5.95 \pm 0.06 \mathrm{a}$ & $5.93 \pm 0.06 \mathrm{~b}$ & $6.14 \pm 0.04 \mathrm{c}$ \\
$\mathrm{TVB}-\mathrm{N}(\mathrm{mg} / 100 \mathrm{~g}) \pm \mathrm{SD}$ & $15.93 \pm 0.80 \mathrm{a}$ & $20.81 \pm 1.02 \mathrm{~b}$ & $33.39 \pm 1.06 \mathrm{c}$ \\
\hline
\end{tabular}

During the first 7 days $\mathrm{pH}$ values decreased significantly and reached their highest values at the end of the study (Table 2). During the first 2 - $3 \mathrm{~h}$ after slaughter $\mathrm{pH}$ values decrease due to lactic acid production in red muscle. For white muscle, such as chicken breast, $\mathrm{pH}$ values continue decreasing for another $24 \mathrm{~h}$, reaching values of 5.6 - 5.4 (Richardson \& Mead 2001). The increase recorded in the last few days could be due to a reduction in electrolyte dissociation and an increase in ammonia formation (Ko, Ma, \& Song, 2005; Chu, Kim, Lee, Yu, \& Song, 2009).

The evolution of major adenine nucleotides and their related compounds can provide information on the biochemical changes occurring during storage and may well be correlated with meat freshness, as in fish. Three ATP derivatives (inosine 5'-monophosphate, inosine, and hypoxanthine) were identified and quantified. The evolution of IMP, Ino and Hx concentrations during storage of packaged sliced chicken breasts is shown in Fig. 3. Initial IMP levels were $4.4 \mu \mathrm{mol} \mathrm{g}^{-1}$, which agrees with other studies on chicken breast (Kavitha \& Modi, 2007), although Cheng et al. (2002) found higher levels. Large variations in nucleotide content in muscles have been found not only due to age, sex, breed, and species (Bailey, 1983, cited by Kavitha \& Modi, 2007) but also between muscles of the same specie (Ellis,, Broadhurst, Clarke, \& Goodacre, 2005). High levels of Ino and low of Hx were found on day 0.

IMP content decreased with storage time, reaching very low levels at days 9,12 , and 14 . Ino concentrations were constant or even showed a slight increase until day 7 of storage, after which a considerable reduction in this compound was observed from this point to the end of storage. Hx showed a slow increase during the first week of storage, increasing rapidly throughout the second week of the study, reaching levels of $6.7 \mu \mathrm{mol} \mathrm{g}^{-1}$ at day 14 . 


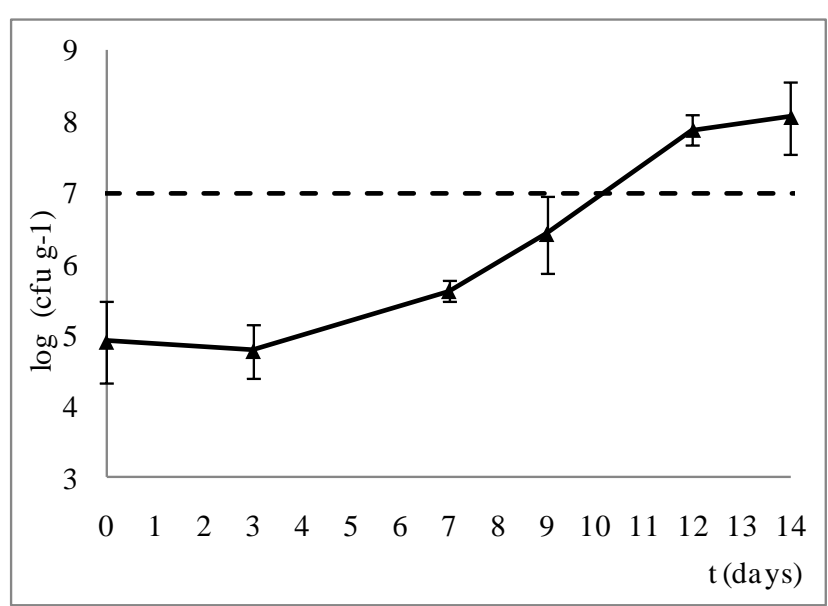

Fig. 2. Aerobic plate counts (APC) for broiler chicken breasts stored at $4^{\circ} \mathrm{C}$ during $0,3,7,9,12$ and 14 days. Bars express standard deviation. The dotted line is the limit of acceptable contamination.

These results indicate that, during the first 7 days, part of the IMP had been transformed to Ino, but that there had been little degradation of Ino to Hx. However, by the end of the second week, the Ino had been completely degraded to $\mathrm{Hx}$, which would imply a large degree of spoilage during this week. Dalgaard (2000) reported that the formation of IMP is due to the autolytic action of enzymes, while bacterial spoilage contributes to Ino and Hx formation. Several authors have also found that the loss of sensory quality is correlated with increases in $\mathrm{Hx}$ level during storage (Giménez, Roncalés, \& Beltrán, 2000; Greene \& Bernatt-Byrne, 1990).

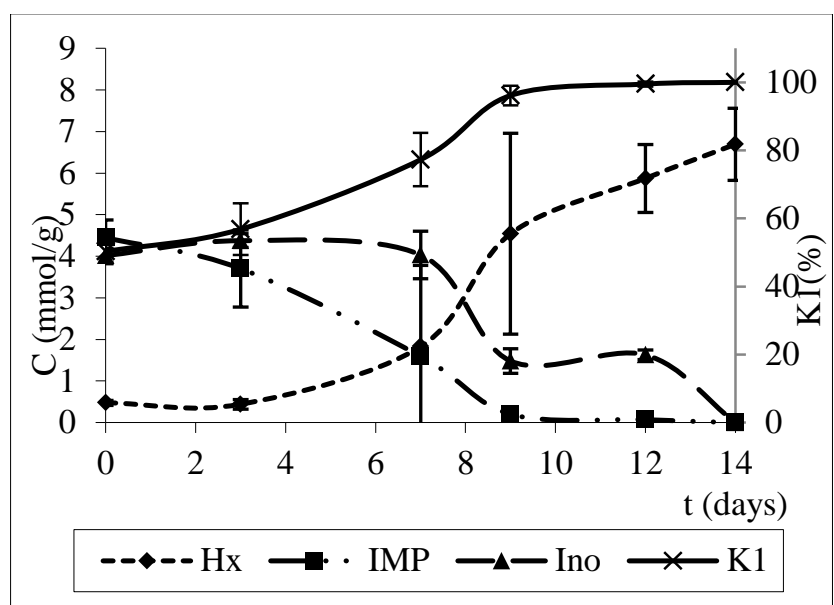

Fig. 3. Changes in concentration of nucleotide compounds (inosine 50 monophosphate -I MP -; inosine - Ino -; hypoxanthine - $\mathrm{Hx}-$ ) and $\mathrm{K}_{1}$ values (with standard deviation bars). Values shown are the means of triplicate measurements.

Botta (1995), working with fish processed during the latter stages of its storage life, observed that the use of $\mathrm{Hx}$ content without any other index of freshness may be misleading. The large variation observed in the rate of nucleotide degradation is probably caused by variation in intrinsic enzyme activity and nucleotide concentrations (Hiltz, Dyer, Nowlan, \& Dingle, 1971, Nychas \& Tassou, 1997). Since the $K_{1}$-value proposed by Saito, Arai, and Matsuyoshi (1959) includes intermediate breakdown products and due to the rapid disappearance of adenosine phosphate, Karube et al. (1984) proposed $\mathrm{K}_{1}$-value, which excludes adenosine-5'-triphosphate, adenosine-5'diphosphate (ADP) and adenosine-5'-monophosphate (AMP). The $\mathrm{K}_{1}$-value has been demonstrated to be a good freshness index in fish. Fig. 3 shows that $\mathrm{K}_{1}$ increased in value from 0 to 9 days of storage, then remained practically constant until the end of the study. This could imply an increase in nucleotide degradation, reaching its maximum at day 9, when the IMP was depleted which could be correlated with the loss of freshness caused by autolytic changes, as well as enzymatic activity of microorganisms. These results are in agreement with the evolution of microbiological counts (Fig. 2).

All these results may indicate that the marketing period for these samples should be less than 12 days, although additional sensory analysis should be carried out to confirm this.

Storage time fitting (Eq. 2) showed a linear relationship between time and TVB-N, log cfu $\mathrm{g}^{-1}, \mathrm{pH}$ and parameter $\mathrm{K}_{1}$, with a $\mathrm{R}^{2}=0.993$. During the spoiling process of chicken meat, freshness decreases, hence microbial numbers reach higher levels and raise TVB-N and $\mathrm{K}_{1}$ levels as a result of converting amino acids to a growth substrate instead of glucose, which increases $\mathrm{pH}$ values. In spite of the fact that it would explain packaged chicken meat spoilage, this relation is not used as a freshness indicator.

Time $=-695.432+592.514 * \mathrm{a}_{\mathrm{w}}+0.104661 * \mathrm{~K}_{1}$

$$
+0.0207147 * \text { TVB-N }+16.5139 * \mathrm{pH}+1.21612 * \log \mathrm{cfu} \mathrm{g}^{-1}
$$

$\mathrm{R}^{2}=99.27 \%$

\subsection{Non-destructive analysis (Image analysis)}

An assessment of the effect of the addition of plastic film was performed on diffuse reflectance data acquired during storage time. The spectra obtained $(\log (1 / \mathrm{R}))$ for each image were classified according to the sampling time (storage time) based on the presence or absence of the packaging film. The images were therefore taken before and after the chicken samples were unpacked. Fig. 4 shows the discriminate results performed on the data of the packaged and unpackaged samples. The first principal component (PC1) explained $73.51 \%$ of total variance, while PC2 explained only $19.7 \%$ of the variation. Although the samples could not be differentiated based on the presence or absence of plastic film at 0 and 7 days, there was a slight difference between the two groups at day 14 of storage. These observations were consistent with the results observed by other authors (Isaksson, Charles, Miller, \& Tormod, 1992), who found that the addition of film to meat samples caused only slight, or negligible, increases in the optimal prediction errors of the NIR and NIT methods. On the other hand, there was a clear discrimination based on storage time ( 0,7 and 14 days). Since the aim of this study was to apply visual and SWNIR techniques to monitoring the freshness of packaged sliced chicken breasts, the slight influence of the packaging film was not taken into account for the 
subsequent studies, considering all samples (with and without packaging film) to be equal.

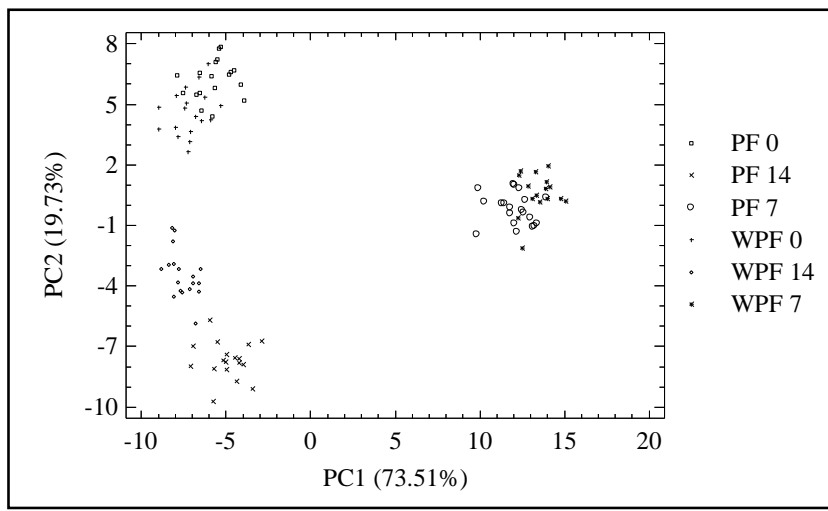

Fig. 4. Discriminate analysis for the spectra $(\log 1 / \mathrm{R})$ of the samples based on the presence of packaging film (PF: with packaging film; WPF: without packaging film) and storage time.

Table 3 shows the statistical results of the Partial Least Squares Discriminant Analysis (PLSDA) employed to obtain the predictive methods of classification according to storage time. The calibration $(\mathrm{C})$ and cross validation (CV) accuracy was given by the standard error (SE), root mean square error (RMSE) and the coefficient of determination $\left(\mathrm{R}^{2}\right)$. Although the determination coefficient for calibration $\left(\mathrm{R}^{2} \mathrm{C}\right)$ was higher for all the times $\left(R^{2}=0.94\right)$, the cross validation coefficient $\left(R^{2} C V\right)$ was only higher for 7 days $\left(\mathrm{R}^{2}=0.82\right)$ and was slightly lower for 0 and 14 days $\left(R^{2}=0.72\right.$ and $R^{2}=0.75$ respectively).

In order to increase the resolution, the numbers of independent variables available were reduced, selecting the main spectrum points with the best correlation with storage time. The wavelengths obtained, employing the variable selection algorithm of IPLSDA, were 413, 426, 449, 460, 473, 480, 499, 638, 942, 946, 967, 970 and 982 $\mathrm{nm}$.

Table 3.

Statistical results of the square regression (PLS). The prediction results for an independent test set are expressed as both the standard error (SE), the root mean square error (RMSE) and the determination coefficient $\left(\mathrm{R}^{2}\right)$ for calibration $(\mathrm{C})$ and cross-validation $(\mathrm{CV})$ model.

\begin{tabular}{lcccccc}
\hline Modelled & \multicolumn{3}{c}{ Entire Spectrum } & \multicolumn{3}{c}{ Thirteen Selected points } \\
Class. & 0 days & 7 days & 14 days & 0 days & 7 days & 14 days \\
\hline SE $(\mathrm{C})$ & 0 & 0 & 0 & 0 & 0 & 0 \\
SE $(\mathrm{CV})$ & 0.1094 & 0 & 0.0781 & 0 & 0 & 0 \\
RMSE $(\mathrm{C})$ & 0.1110 & 0.1193 & 0.1137 & 0.1040 & 0.0933 & 0.1231 \\
RMSE $(\mathrm{CV})$ & 0.2984 & 0.1987 & 0.2878 & 0.1580 & 0.1666 & 0.2236 \\
$\mathrm{R}^{2}(\mathrm{C})$ & 0.9352 & 0.9359 & 0.9419 & 0.9513 & 0.9609 & 0.9318 \\
$\mathrm{R}^{2}(\mathrm{CV})$ & 0.7179 & 0.8673 & 0.7510 & 0.8894 & 0.8754 & 0.7766 \\
\hline
\end{tabular}

The results of the cross and test set validations performed for the predictive models employing the values obtained for the selected wavelengths were better than those obtained employing the entire spectrum (Table 3). The information provided by the whole spectrum could obscure that contributed by the selected points. Thus, information provided at the turning points of the second derivate of the spectra at 525, 560, 570 and $600 \mathrm{~nm}$ (Fig. 5 ) reduced the value of $R^{2}$, for PLS study, to 0.65 when these were added to the study employing only the 13 selected points $\left(\mathrm{R}^{2}=0.89\right)$.

Fig. 5 shows the second derivate of the spectra for all storage times and the selected wavelengths using the IPLSDA algorithm. The second derivative technique is often used to process NIR data. It helps to separate overlapping absorption bands, remove baseline shifts and increase apparent spectral resolution (Lin et al., 2004), although the derivatives are notoriously sensitive to noise (Tsai \& Philpot, 1998). Most selected wavelengths were in the range 400-500 and 940-980 $\mathrm{nm}$, although wavelengths around $638 \mathrm{~nm}$ were influential too. Some authors have correlated some wavelengths of the visible and SW-NIR spectrum with biochemical components that change during meat storage (Liu, Lyon, Windham, Realini, \& Pringle, 2003; Andrés, Silva, Soars-Pereira, Martins, BrunoSoares, \& Murray, 2008). This correlation is related mainly to the vibrational frequency which is a function of the masses of the two atoms $m_{1}$ and $m_{2}$ and the strength of the bond $k$ and there is a parabolic relationship between potential energy and interatomic distance. When the frequency of the radiation matches that of the vibrating molecule, there will be a net transfer of energy from the radiation to the molecule which can be measured as a plot of energy versus wavelength called a Spectrum (Osborne, 2000). The wavelengths $430-435 \mathrm{~nm}$ form the Soret band attributed to an intense $\pi \rightarrow \pi^{*}$ transition observed in all conjugated porphyrin (macrocyclic tetrapyrrole) rings in which electron delocalisation extends throughout the macrocyclic ring (e.g. the haem prosthetic group in myoglobin Mb) (Liu et al., 2003; Andrés et al., 2008). The absorption bands at 545, 575 and $635 \mathrm{~nm}$ suggest a dynamic conversion and degradation for a number of myoglobin derivatives (Liu et al., 2003). The low levels of red pigments (myoglobin derivatives) in chicken breasts could be responsible for the changes observed at $638 \mathrm{~nm}$. A weak near infrared band at $760 \mathrm{~nm}$ could be due to the $\mathrm{OH}$ third overtone or an absorption band produced by myoglobin oxidation. Moreover, characteristic bands of water were identified at $980 \mathrm{~nm}(\mathrm{OH}$ second overtone $)$ (Liu et al., 2003; Andrés et al., 2008).

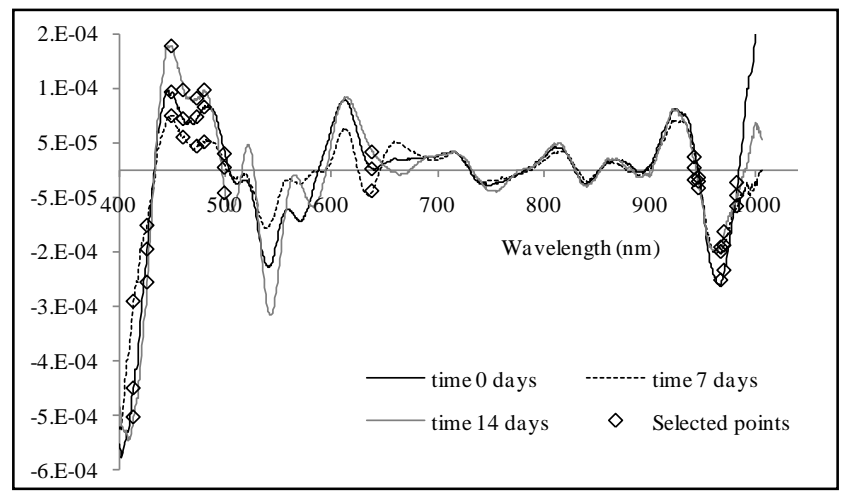

Fig. 5. Second derivative of the spectra for all storage times; $(\diamond)$ Points selected by IPLSDA.

Differences between the spectra for the sampling time with those obtained at day 0 are shown in Fig. 6. The greatest differences were obtained, for all selected 
wavelengths, between time 0 and 14 days. The maximum differences between time 0 and 7 days were in the range of 460 and $499 \mathrm{~nm}$. This wavelength range could mainly differentiate between samples at 0 days and days 7 and 14, but not between days 7 and 14 (lowest difference). Selected wavelengths before $460 \mathrm{~nm}$ and after $499 \mathrm{~nm}$ could be responsible for discriminating between 7 and 14 days, since the differences between them were the greatest.

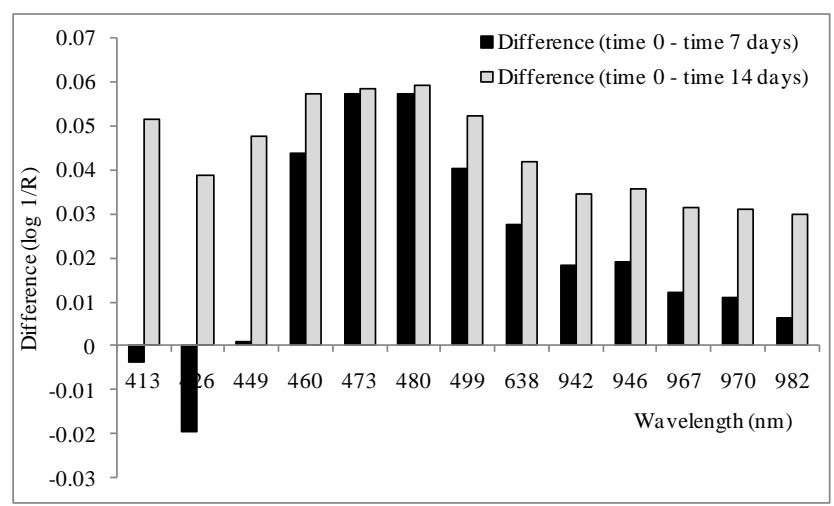

Fig. 6. Differences between spectra at 7 and 14 day to those obtained at day 0 for the selected wavelength.

3.3. Correlation between image analysis (non-destructive analysis) and the physicochemical, biochemical and microbiological analyses (destructive analysis).

A partial least square regression (PLS) was performed to detect the variation of the spectrum at the selected point during storage time with the physicochemical, biochemical and microbiological parameters (Table 4). The highest determination coefficient for prediction $\left(\mathrm{R}^{2} \mathrm{P}\right)$ was obtained for $\mathrm{K}_{1}, \mathrm{TVB}-\mathrm{N}, \mathrm{pH}, \mathrm{a}_{\mathrm{w}}$ and cfu $\mathrm{g}^{-1}$, indicating a relation among these five parameters. Similar behaviors were found by other authors who worked on larger wavelengths and observed a connection between spectral changes in meat and fish samples and a decrease of freshness associated with microbial growth (Ellis et al. 2002; Lin et al., 2004, 2006, Horváth, Seregély, Andrássy, Dalmadi \& Farkas, 2008).

Table 4.

Statistical results of the square regression (PLS). The prediction results for an independent test set are expressed as both the root mean square error (RMSE) and the determination coefficient $\left(\mathrm{R}^{2}\right)$ for calibration $(\mathrm{C})$ and predictive $(\mathrm{P})$ models.

\begin{tabular}{lcccccc}
\hline & $\mathrm{x}^{\mathrm{W}}$ & $\mathrm{a}_{\mathrm{w}}$ & $\mathrm{pH}$ & $\begin{array}{c}\text { TVB-N } \\
(\mathrm{mg} / 100 \mathrm{~g})\end{array}$ & $\mathrm{K}_{1}$ & $\begin{array}{c}\log (\mathrm{cfu} \\
\left.\mathrm{g}^{-1}\right)\end{array}$ \\
\hline RMSE (C) & 0.3130 & 0.0009 & 0.0693 & 3.8190 & 4.1478 & 0.7264 \\
RMSE (P) & 0.4210 & 0.0016 & 0.0834 & 6.0118 & 6.5294 & 0.7994 \\
$\mathrm{R}^{2}(\mathrm{C})$ & 0.352 & 0.756 & 0.580 & 0.736 & 0.799 & 0.789 \\
$\mathrm{R}^{2}(\mathrm{P})$ & 0.593 & 0.878 & 0.767 & 0.883 & 0.893 & 0.804 \\
\hline
\end{tabular}

\section{Conclusions}

The loss of freshness in sliced and packaged chicken breast has mainly been associated with an increase in the values of TVB-N, parameter $\mathrm{K}_{1}, \mathrm{pH}, \mathrm{a}_{\mathrm{w}}$ and the microbial loads $\left(\mathrm{cfu} \mathrm{g}^{-1}\right)$. The spectra obtained from sliced and packaged chicken breast images using visible and SWNIR spectroscopy have been related to storage time of the samples, where the best wavelengths for modeling freshness were 413, 426, 449, 460, 473, 480, 499, 638, 942, 946, 967, 970 and $982 \mathrm{~nm}$. The presence of packaging film did not affect the information obtained from the images. Of special interest is the linear correlation between the visible and SW-NIR spectroscopy and parameters such as the $\mathrm{K}_{1}$ and TVB-N indexes, which indicates the simultaneous evolution of certain metabolites (inosine 5'-monophosphate, inosine and hypoxanthine). The visible and SW-NIR spectroscopy method we report herein is fast, low-cost and non-destructive and we consider it suitable for monitoring the freshness of sliced and packaged chicken breast. Further repeatability, reliability and accuracy studies, using other packaging methods, will be carried out in due course.

\section{Acknowledgements}

We wish to thank the Polytechnic University of Valencia and Generalitat Valenciana for the financial support they provided through the PAID-06-08-3251 and GVPRE/2008/170 Projects, respectively.

\section{References}

Alain, K., \& Stéphane, P. (2008). Effect of superheated steam on the inactivation of Listeria innocua surfaceinoculated onto chicken skin. Journal of Food Engineering, 87(2), 162-171.

Andrés S., Silva A., Soares-Pereira A.L., Martins C., Bruno-Soares A.M., \& Murray I. (2008). The use of visible and near infrared reflectance spectroscopy to predict beef $M$. longissimus thoracis et lumborum quality attributes. Meat Science, 78, 217-224.

Bailey, M,E. (1983). The Maillard reaction and meat flavour. In G. R. Walter, \& M. S. Feather (Eds.), The Maillard reaction in foods and nutrition (pp. 169-184). Washington, DC: American Chemicals Society.

Barat J.M., Gil L., García-Breijo E., Aristoy M.C., Toldrá F., Martínez-Máñez R., \& Soto J. (2008). Freshness monitoring of sea bream (Sparus aurata) with a potentiometric sensor. Food Chemistry, 108, 681-688.

Bharati, M. H. \& Champagne, M. (2004). Using nearinfrared multivariate image regression to predict pulp properties. Tappi journal vol 3, n⿳05, pp 8-14.

Botta, J. R. (1995). Evaluation of seafood freshness quality. New York, NY: VCH Publishers Inc., p. 180.

Brereton, R.G. (1992). Multivariate Pattern Recognition in Chemometrics illustrated by case studies. In R.G.Brereton (Ed.). Amsterdam: Elsevier.

Burns, B. G., \& Kee, P. J. (1985). Liquid chromatographic determination of hypoxanthine content in fish tissue. Journal of the Association of Official Analytical Chemists, 68, 444-448.

Chun, H.H., Kim, J.Y., Lee, B.D., Yu, D.J., \& Song, K.B. (2009). Effect of UV-C irradiation on the inactivation of inoculated pathogens and quality of chicken breasts during storage. doi:10.1016/j.foodcont.2009.06.006.

Dalgaard, P. (1995). Qualitative and quantitative characterization of spoilage bacteria from packed fish. 
International Journal of Food Microbiology, 26, 319333.

Dalgaard, P. (2000). Freshness, Quality and Safety in Seafoods. Flair-Flow Europe Technical Manual. F-FE 380A/00.

Dufour, E., Frencia, J.P., \& Kanea, E. (2003). Development of a rapid method based on front-face fluorescence spectroscopy for the monitoring of fish freshness. Food Research International, 36, 415-423.

Economou, T., Pournis, N., Ntzimani, A., \& Savvaidis, I.N. (2009). Nisin-EDTA treatments and modified atmosphere packaging to increase fresh chicken meat shelf-life. Food Chemistry (114), 1470-1476.

EEC (2005). COMMISSION REGULATION (EC) No 2074/2005 of 5 December 2005. Laying down implementing measures for certain products under Regulation (...). Section II, Chapter I: TOTAL VOLATILE BASIC NITROGEN (TVB-N) LIMIT VALUES FOR CERTAIN CATEGORIES OF FISHERY PRODUCTS AND ANALYSIS METHODS TO BE USED. Official Journal of the European Union, L 338/36.

EEC (2007). COMMISSION REGULATION (EC) No $1441 / 2007$ of 5 December 2007. Microbiological criteria for foodstuffs. Official Journal of the European Union, L 322/12.

Ellis, D.I., \& Goodacre, R. (2001). Rapid and quantitative detection of the microbial spoilage of muscle foods: current status and future trends. Trends in Food Science \& Technology, 12, 414-424.

Ellis, D.I., Broadhurst, D., Kell, D.B., Rowland, J.J., \& Goodacre, R. (2002). Rapid and quantitative detection of the microbial spoilage of meat by Fourier transform infrared spectroscopy and machine learning. Applied and Environmental Microbiology, 68, 2822-2828.

Ellis, D.I., Broadhurst, D., \& Goodacre, R. (2004). Rapid and quantitative detection of the microbial spoilage of beef by Fourier transform infrared spectroscopy and machine learning. Analytica Chimica Acta, 514, 193 201.

Ellis, D.I., Broadhurst, D., Clarke, S.J., \& Goodacre, R. (2005). Rapid identification of closely related muscle foods by vibrational spectroscopy and machine learning. Analyst, 130, 1648-1654.

Fernández-Segovia, I., Escriche, I., \& Serra, J.A. (2008). Evolution of volatile fraction and ATP related compounds during storage of desalted cod (Gadus morhua). Food Science and Technology International, 14(5), 37-47.

Flores, M., Armero, E., Aristoy, M.C., \& Toldrá, F. (1999). Sensory characteristics of cooked pork loin as affected by nucleotide content and post-mortem meat quality. Meat Science, 51, 53-59

Fuentes, A., Barat, J. M., Fernández-Segovia, I., \& Serra, J. A. (2008). Study of sea bass (Dicentrarchus labrax L.) salting process: Kinetic and thermodynamic control. Food Control, 19, 757-763.

Giménez, B., Roncalés, P., \& Beltrán J.A. (2000). Different packaging conditions to improve shelf-life of filleted rainbow trout. In: Gudjónsson A. and Niclasen
O. (eds.), Prooceedings of 30th WEFTA Plenary Meeting. Tórshavn, Faeroe Islands: FØroya Fródskaparfelag pp. 43-50.

Greene D.H. \& Bernatt-Byrne E.I. (1990). Adenosine trriphosphate catabolites as flavour compounds and frehness indicators in Pacific cod (Gadus macrocephalus) and pollock (Theragra chalcogranama). Journal of Food Science 55: 257-258.

Hiltz, D.F., Dyer, W.J., Nowlan, S., \& Dingle J.R. (1971). Variation of biochemical quality indices by biological and technological factors. In: Kreuzer R. (ed.), Fish Inspection and Quality Control. London: Fishing News (Books) Limited pp. 191-195.

Horváth, K, Zs., Seregély, É., Andrássy, I., \& Dalmadi, J. F. (2008). A Preliminary Study Using Near Infrared Spectroscopy to Evaluate Freshness and Detect Spoilage in Sliced Pork Meat. Acta Alimentaria, Vol. 37, Nr.1, 93-102.

Huff-Lonergan, E. \& Lonergan S. M. (2005). Mechanisms of water-holding capacity of meat: The role of postmortem biochemical and structural changes (Review). Meat Science 71, 194-204.

In-Seon, P., Yong-Jin, Ch., \& Namsoo, K. (2000). Characterization and meat freshness application of a serial three-enzyme reactor system measuring ATPdegradative compounds. Analytica Chimica Acta 404, $75-81$.

Isaksson, T, Charles, E. M., \& Tormod N. (1992). Nondestructive NIR and NIT Determination of Protein, Fat, and Water in Plastic-Wrapped, Homogenized Meat. Applied Spectroscopy. Vol 46, Nr 11, 16851694

Johnson, E. \& Stevenson, R. (Eds.). (1978). Quantitative analysis in basic liquid chromatography (pp. 223). Hansen Way, Palo Alto, CA.: Varian Associates.

Kaneki, N., Miura, T., Shimada, K., Tanaka, H., Ito, S., \& Hotori, K. (2004). Measurement of pork freshness using potentiometric sensor. Talanta, 62, 217-221.

Karube, I., Matsuoka, H., Suzuki, S., Watanabe, E., \& Toyama, K. (1984). Determination of fish freshness with an enzyme sensor system. Journal of Agricultural and Food Chemistry, 32(1), 314-319.

Kavitha, S. \& Modi, V.K. (2007). Effect of water activity and temperature on degradation of 5 '-inosine monophosphate in a meat model system. LWT - Food Science and Technology, 40, 1280-1286

Ko, J. K., Ma, Y. H., \& Song, K. B. (2005). Effect of chlorine dioxide treatment on microbial growth and qualities of chicken breast, Journal of Food Science and Nutrition 10 (2), 122-129.

Lin, M., Al-Holy, N., Mousavy-Hesary, M., Al-Qadiri, H., Cavinato, A. G., \& Rasco, B.A. (2004). Rapid and quantitative detection of the microbial spoilage of chicken breasts by diffused reflectance spectroscopy (600-1100 nm). Lett. appl. Microbiol., 39, 148-155.

Lin, M., Mousavi, M., Al-Holy, M., Cavinato, A. G., \& Rasco, B. A. (2006). Rapid near infrared spectroscopic method for the detection of spoilage in rainbow trout (Oncorhynchus mykiss) fillet. Journal. Food Science, 71(1), S18-S23. 
Liu, Y., Lyon, B. G., Windham, W. R., Realini, C. E., Pringle, T. D. D., \& Duckett, S. (2003). Prediction of color, texture, and sensory characteristics of beef steaks by visible and near infrared reflectance spectroscopy. A feasibility study. Meat Science, 65, 1107-1115.

Malle, P. \& Tao, S. H. (1987). Rapid Quantitative Determination of Trimethylamine using Steam Distillation. Journal of Food Protection 50, (9), 756760.

Martens, H. \& Naes, T. (1989). Multivariate calibration. J. Wiley and Sons, Chichester, UK.

Mateo, J., Domínguez, M.C., Aguirrezábal, M.M., \& Zumalacárregui, J.M. (1996). Taste compounds in chorizo and their changes during ripening. Meat Science, 44(4), 245-254.

Mayes, D. M., \& Callis, J. B. (1989). A photodiode-arraybased near-infrared spectrophotometer for the 600 $1100 \mathrm{~nm}$ wavelength region. Applied Spectroscopy, $43,27-32$.

Nádai, B.T. (1983). Preliminary experiments for measuring meat composition by near infrared reflection technique. Acta Alimentaria, 12, 119-130.

Nádai, B.T. \& Mihályi-Kengyel, V. (1984). Investigations of different equations predicting moisture, fat and protein content of raw meat by NIR- technique. Acta Alimentaria, 13, 343-353.

Nilsen, H., Esaiassen, M., Heia, K., \& Sigernes, E. (2002). Visible/near infrared spectroscopy. A new tool for the evaluation of fish freshness. Journal of food Science, 67, 1821-1826.

Nychas, G. J. E. \& Tassou, C. C. (1997). Spoilage processes and proteolysis in chicken as detected by HPLC. Journal of the Science of Food and Agriculture, 74, 199-208.

Osborne, Brian G. (2000). Near-infrared Spectroscopy in Food Analysis. In: Robert A. Meyers. (ed.), Encyclopedia of Analytical Chemistry: Applications, Theory and Instrumentation Volume 12: Electronic Absorption and Luminescence, Gas Chromatography, Infrared Spectroscopy, Kinetic Determinations. New York: John Wiley \& Sons Inc, pp. 1-14.

Pascual, A. M., \& Calderón, P. V. (2000). Microbiología alimentaria: metodología analítica para alimentos y bebidas. Díaz de Santos S.A. Madrid.

Pink, J., Naczk, M., \& Pink, D. (1999). Evaluation of the quality of frozen minced red hake: use of Fourier transform near-infrared spectroscopy. Journal of Agricultural and Food Chemistry, 47, 4280-4284.

Richardson, R. I. \& Mead, G.C. (2001). Ciencia de la Carne de Ave. Acribia, S. A. Zaragoza.

Saito, T., Arai, K., \& Matsuyoshi, M. (1959). A new method for estimating the freshness of fish. Bulletin of the Japanese Society of Scientific Fisheries, 24, 749752.

Sinelli, N. (2006): Monitoring the shelf life of dairy products. New Fd (4) 38-39; 42-44.
Sinelli, N., Barzaghi, S., Giardina, C., \& Cattaneo, T.M.P. (2005). A preliminary study using Fourier transform near infrared spectroscopy to monitor the shelf-life of packed industrial ricotta cheese. Journal of Near Infrared Spectroscopy, 13, 293-300.

Smolander, M., Alakomi, H., Ritvanen, T., Vainionpää, J., \& Ahvenainen, R. (2004). Monitoring of the quality of modified atmosphere packaged broiler chicken cuts stored in different temperature conditions. A Timetemperature indicators as quality-indicating tools. Food Control, 15, 217-229.

Surette, M. E., Gill, T. A., \& Leblanc, P. J. (1988). Biochemical basis of post-mortem nucleotide catabolism in cod (Gadus morhua) and its relationship to spoilage. Journal of Agricultural and Food Chemistry, 36, 19-22.

Tsai, F. \& Philpot, W. (1998). Derivative Analysis of Hyperspectral Data. Remote Sensing of Environment, 66, 41-51.

UNE-EN ISO R1442. (1979). International Standards Organisation. Determination of Moisture.

UNE-EN ISO 4833:2003 standard (AENOR, 2003). Microbiology of food and animal feeding stuffs. Horizontal method for the enumeration of microorganisms. Colony-count technique at 30 degrees C.

Wallays, C., Missotten, B., De Baerdenmaeker, J., \& Saeys, W. (2009). Hyperspectral waveband selection for on-line measurament of grain cleanness. Biosystems Engineering, 104(1), 1-7.

Warm, K., Martens, H., \& Nielsen, J. (2001). Sensory quality criteria for five fish species predicted from near infrared (NIR) reflectance measurement. Journal of Food Quality, 24, 389-403.

Watanabe, A., Tsuneishi, E., \& Takimoto, Y. (1989). Analysis of ATP and its breakdown products in beef by reversed-phase HPLC. Journal of Food Science, 54, 1169-1172.

Williams, P.C. \& Norris, K. (2001). Near-infrared technology in the agricultural and food industries, 2nd ed, American Association of Cereal Chemists, St. Paul, Minn.

Wu D, He Y., \& Feng S. (2008). Short-wave near-infrared spectroscopy analysis of major compounds in milk powder and wavelength assignment. Analytica Chimica Acta, V. 610, (2), 232-242.

Zhang, W.G., Lonergan, S. M., Gardner, M. A., \& HuffLonergan, E. (2006). Contribution of postmortem changes of integrin, desmin and $\mu$-calpain to variation in water holding capacity of pork. Meat Science, 74:578-585.

Zhang, Z., Jin, T., Dong-hui, Ch., \& Yu-bin, L. (2008). Electronic Nose with an Air Sensor Matrix for Detecting Beef Freshness. Journal of Bionic Engineering, 5, 67-73. 